\title{
Efecto embriotóxico y teratogénico de Ruta chalepensis L. "ruda», en ratón (Mus musculus)
}

\author{
Embryotoxic and teratogenic effect of Ruta chalepensis L. «rue», in \\ mouse (Mus musculus)
}

\author{
José Gonzales, Victor Benavides, Ruth Rojas y José Pino
}

\begin{abstract}
Universidad Nacional Mayor de San Marcos, Facultad de Ciencias Biológicas, Instituto de Investigación de Ciencias Biológicas Antonio Raimondi

José Gonzales: Laboratorio de Reproducción y Biología del Desarrollo. Facultad de Ciencias Biológicas. Universidad Nacional Mayor de San Marcos. Casilla Postal 11-058. Lima 11. Lima, Perú. Email: ppgonda@gmail.com
\end{abstract}

\section{Resumen}

Ruta graveolens L. y R. chalepensis L. son plantas usadas en medicina folclórica como antiespasmódicos, antihelmínticos, antimicrobianos, emenagogos y abortivos. En el presente trabajo se evaluó el efecto del extracto acuoso liofilizado (EAL) de las hojas de $R$. chalepensis en embriones postimplantacionales de ratón. Ratonas albinas preñadas recibieron intraperitonalmente (ip) $10 \mathrm{mg}$ de ruda liofilizada/kg de peso corporal (grupo tratado, $\mathrm{n}=12$ ) durante el periodo post-implantacional (día 9 - día 17 post-cópula), y un grupo control(C), n=18, que recibió sólo agua destilada durante el mismo período. El EAL de ruda no afectó negativamente el peso de la madre pero sí del útero durante el tratamiento $(p<0,05)$. En el grupo tratado la frecuencia de reabsorciones fetales fue mayor $(p<0,05)$ y el peso fetal fue significativamente menor en comparación con el control $(p<0,01)$. Además en el grupo tratado se evidenció la presencia de malformaciones esqueléticas. En conclusión, encontramos que el EAL de $R$. chalepensis muestra efectos embriotóxicos en ratones expuestos durante el período postimplantacional.

Palabras clave: Ruta chalepensis, embriotoxicidad, teratogenicidad, ratón, postimplantacional.

\section{Abstract}

Ruta graveolens $\mathrm{L}$. and $R$. chalepensis $\mathrm{L}$. are plants used in folkloric medicine as antispasmodics, antihelmintics, antimicrobials, emmenagoges and abortifacients. In this work we evaluated embryotoxic effect of liophilized aqueous extract (LAE) of leaves of $R$. chalepensis on postimplantational mouse embryos. Pregnant albino mice received intraperitoneally (ip) $10 \mathrm{mg}$ of liophilzed rue/kg of body weight (treated group, $n=12$ ) during post implantational period (day 9 - day 17 postcopula), and a control (C) group, $n=18$, received only distilled water during the same period of time. The LAE of $R$. chalepensis did not affect negatively the weight of mother but affected the weight of the uterus during the period of treatment $(p<0,05)$. The frequency of fetal resorptions was greater $(p<0,05)$ and a significant decrease of fetal weight $(p<0,01)$ was evidenced in fetuses of the treated group in comparison with the $C$ group. Also there was occurrence of skeletal malformations in the treated group. In conclusion, we found that LAE of $R$. chalepensis shows embryotoxic effects on mouse esposed during postimplantational period.

Keywords: Ruta chalepensis, embriotoxicity, teratogenicity, mouse, postimplantational.

\section{Introducción}

La exposición materna a xenobióticos durante el embarazo puede tener diversos efectos en el desarrollo del embrión dependiendo del período de la exposición (Lemonica, 1996). La sincronización de la exposición a una droga es crítica para sus posibles efectos teratogénicos sobre el feto; el período de mayor sensibilidad a compuestos teratogénicos es durante la organogénesis temprana (Stanley \& Bower, 1986).

Ruta chalepensis L. (Rutaceae), «ruda», fue introducido en América después de la conquista española (Zeichen et al, 2000). Es frecuentemente usada por sus propiedades medicinales (Arenas \& Savitry, 1994). Las hojas y yemas jóvenes contienen alcaloides, flavonoides, fenoles, aminoácidos, fucomarinas y saponinas (Hnatyszyn et al., 1974). La ruda también es conocida por tener actividad como emenagogo, antihelmíntico, espasmolítico, antirreumático (Fon Quer, 1962; Di Stasi et al., 1994; Chávez et al., 2003), antihipertensivo (Berdoncés, 1998), antiséptico para la piel y repelente (Guarrera, 1999; González, 1998), antifungicida e insecticida (Mancebo et al., 2002; Trovato et al., 2000; Ojala et al., 2000). Ruda puede causar también sangrado uterino en mujeres embarazadas, con posible muerte fetal (Camargo, 1985 citado por Melito et al., 2003). Reportes de etnobotánica indican que es consumida por gente indígena para promover la menstruación, la expulsión fetal y como abortivo (Conway \& Slocumb, 1979). Guerra \& Andrade (1978) y Kong et al., (1989), encontraron efectos de la ruda en la implantación de embriones y un aumento de reabsorciones uterinas; mientras que estudios de Gonçalves et al. (2005) no confirmaron estos efectos. Algunos estudios sugieren un efecto negativos de $R$. graveolens sobre el desarrollo pre y postimplantacional en ratones (Benavides et al, 2000). En el presente trabajo se evaluó el efecto del extracto acuoso liofilizado (EAL) de las hojas de R. chalepensis sobre embriones postimplantacionales de ratón.

\section{Materiales y métodos}

R. chalepensis fue obtenido en comercios locales (Lima, Perú), e identificado en el Departamento de Botánica de la Facultad de Ciencias Biológicas de la Universidad Nacional Mayor de San Marcos. Las hojas fueron secadas en una estufa a $55^{\circ} \mathrm{C}$ por 24 horas luego pesadas y pulverizadas; el polvo fue dejado con agua destilada por 24 horas a $55^{\circ} \mathrm{C}$ para obtener el extracto acuoso, el cual fue filtrado y liofilizado. Luego el extracto acuoso liofilizado de ruda fue resuspendido en agua destilada y guardada a $-20{ }^{\circ} \mathrm{C}$. 
Tabla 1. Ganancia de peso materno en ratones hembra tratadas intraperitonealmente con extracto acuoso liofilizado de $R$. chalepensis $(10 \mathrm{mg} / \mathrm{kg}$ ) o agua destilada del día 9 al 17 del período de gestación.

\begin{tabular}{|c|c|c|}
\hline & Control & $10 \mathrm{mg} / \mathrm{kg}$ \\
\hline Hembras preñadas & 18 & 12 \\
\hline Peso de útero con fetos $(\mathrm{g})$ & $9,43 \pm 0,99$ & $3,57 \pm 1,22^{*}$ \\
\hline \multicolumn{3}{|l|}{ Peso materno } \\
\hline Día 1 & $27,71 \pm 1,00$ & $26,95 \pm 0,73$ \\
\hline Día 9 & $30,06 \pm 0,90$ & $30,33 \pm 0,71$ \\
\hline Día 18 & $40,96 \pm 1,64$ & $34,49 \pm 1,67^{*}$ \\
\hline Día 18 corregido (menos el peso del útero) & $31,53 \pm 1,07$ & $30,92 \pm 0,75$ \\
\hline \multicolumn{3}{|l|}{ Ganancia de peso materno (g) } \\
\hline Día 1-9 & $2,35 \pm 0,41$ & $3,40 \pm 0,35$ \\
\hline Día 9-18 & $10,93 \pm 1,00$ & $4,08 \pm 1,42^{*}$ \\
\hline Día $1-18$ & $12,70 \pm 1,07$ & $7,54 \pm 1,61^{*}$ \\
\hline Día 1-18 corregido (menos el peso del útero) & $3,84 \pm 0,61$ & $3,98 \pm 0,89$ \\
\hline
\end{tabular}

Control vs. tratado ${ }^{*} \mathrm{P}<0,05$ Datos paramétricos; ANOVA test y Bonferroni t-test. Datos no Parametritos; Kruskal-Wallis y Mann-

Whitney Utest SE. error estandar de la media

Se utilizaron ratones de 6 a 10 semanas de edad de la cepa albina Swiss Rockefeller. Los animales fueron mantenidos bajo condiciones estándar con $22-24^{\circ} \mathrm{C}$ de temperatura; fotoperíodo (14h luz: $10 \mathrm{~h}$ oscuridad) con libre acceso al alimento (PurinaPerú) y agua ad libitum.

Ratones hembra, en etapa de estro o proestro, fueron cruzadas con un macho semental toda la noche y la presencia del tapón vaginal al día siguiente fue señal de que ocurrió la cópula y fue tomado como día 1(D1) de la preñez. Las ratonas preñadas fueron divididas en dos grupos; el grupo tratado $(n=12)$ que recibió intraperitonalmente (ip) $10 \mathrm{mg}$ de ruda liofilizada/ $\mathrm{kg}$ de peso corporal durante el periodo post-implantacional (día 9 - día 17 post-cópula), y un grupo control $(\mathrm{C})(\mathrm{n}=18)$ que recibió sólo agua destilada ip durante el mismo período de tiempo.

El día 18 post-cópula, las hembras fueron sacrificadas por dislocación cervical. Cada útero con fetos fue pesado y evaluado a fin de determinar: número de sitios de implantación, fetos vivos, muertos y reabsorciones fetales; además se contaron el número de cuerpos lúteos en los ovarios. Las malformaciones externas fueron inmediatamente evaluados en los fetos vivos, los cuales luego fueron pesados y subsecuentemente aclarados con hidróxido de potasio $1 \%$ y coloreados con rojo de Alizarina y azul Alciano para la evaluación esquelética (Kimmel \& Trammel, 1981; Narotsky \& Rogers, 2000).

La unidad de comparación fue la ratona preñada o la camada (Narotsky \& Rogers, 2000). Las hembras que murieron o tuvie- ron sólo un sitio de implantación fueron excluidas del análisis estadístico. Los datos paramétricos fueron analizados por ANOVA y los no paramétricos por la prueba de Kruskal-Wallis y los resultados corroborados por Bonferroni t-test y Mann-Whitney Utest respectivamente. Un nivel de probabilidad menor del 5\% fue considerado significativo.

\section{Resultados}

No hubo muerte materna en este trabajo. El peso del útero fue menor en el grupo tratado con ruda en comparación del grupo control (Tabla1). Los parámetros reproductivos como fetos vivos y peso fetal fueron menores, mientras que el número de reabsorciones fetales se incrementó en el grupo tratado en comparación del grupo control (Tabla 2). Anomalías externas como exocefalia fueron observadas en ambos grupos mientras que la malformación de espina bífida solo se observó en el grupo tratado con ruda. Hubo ocurrencia de malformaciones esqueléticas como hemivértebra en los tratados con R. chalepensis.

\section{Discusión}

En trabajos con R. graveolens, Gonçalves et al., (2005) no encontró indicios de toxicidad materna en ratones, pero observó diferencias significativas en el peso del feto; en contraste con Melito et al., (2003) que no encontró ninguna diferencia en el peso fetal por camada; mientras que en nuestro trabajo el extracto acuoso liofilizado de $\mathrm{R}$. chalepensis administrado ip no mostró toxicidad materna pero se evidenció diferencias significativas en el peso fetal. Almeida y Lemonica(2000) consideran que el peso fetal no es un

Tabla 2. Parámetros reproductivos en ratones hembra tratados con extracto acuoso liofilizado de $R$. chalepensis (10 mg/kg) o agua destilada del día 9 al 17 del período de gestación.

\begin{tabular}{|c|c|c|}
\hline & Control & $10 \mathrm{mg} / \mathrm{kg}$ \\
\hline Número de madres preñadas & 18 & 12 \\
\hline Número de cuerpos lúteos & $10,33 \pm 0,59$ & $10,42 \pm 1,15$ \\
\hline Sitios de implantación (mean \pm S.E.) & $7,89 \pm 0,76$ & $8,83 \pm 0,88$ \\
\hline Fetos vivos (mean \pm S.E.) & $6,11 \pm 0,91$ & $2,67 \pm 1,05^{*}$ \\
\hline Reabsorciones (mean \pm S.E.) & $1,22 \pm 0,33$ & $4,25 \pm 1,08^{*}$ \\
\hline Fetos muertos (mean \pm S.E.) & $0,56 \pm 0,34$ & $1,92 \pm 0,90$ \\
\hline Peso fetal $(\mathrm{g})$ (mean \pm S.E.) & $0,93 \pm 0,03$ & $0,72 \pm 0,06^{*}$ \\
\hline Peso total de la camada (mean \pm S.E.) & $5,81 \pm 0,69$ & $4,51 \pm 0,53$ \\
\hline
\end{tabular}

Control vs. tratado ${ }^{*} \mathrm{P}<0,05$ Datos paramétricos; ANOVA test y Bonferroni t-test. Datos no Parametritos; Kruskal-Wallis y Mann-

Whitney Utest SE. error estandar de la media 
parámetro concluyente en los estudios de desarrollo debido a que esto puede variar dependiendo del número fetos de la camada. Con respecto a los parámetros reproductivos, los datos muestran que $R$. chalepensis provoca una variación negativa en el número de fetos vivos; además, se evidenció un incremento del número de reabsorciones fetales. Existen pocos reportes sobre toxicidad fetal provocado por esta especie de ruda, los trabajos existentes son en R. graveolens que utilizan extractos alcohólicos o con cloroformo, obteniendo diferentes resultados (Gonçalvez et al., 2005; Melito et al., 2005).

Zeichen et al., (2000) reportó que R. chalepensis, tiene un efecto embriotóxico, realizó evaluaciones histopatológicas, hallando la inhibición del desarrollo del timo que alteraría la migración celular en el sistema nervioso central, provocando que los ratones disminuyan de peso.

En este trabajo la exposición a $R$. chalepensis fue durante el período organogénico, fase más sensible a xenobióticos, con la intención de evaluar el posible efecto embriotóxico y teratogénico de esta planta.

Sin embargo el alto índice de embriotoxicidad provocado por R. chalepensis, no hizo posible hacer conclusiones con respecto a su efecto teratogénico, ya que disminuyó el número de camadas con fetos; en los pocos fetos evaluados se evidenció malformaciones como hemivertebra, exocefalia y espina bifida, mas no es posible aseverar que estas ocurrencias sean debido al tratamiento; esto hace necesario la evaluación de un mayor número de camadas para poder determinar sus efectos teratogénicos.

En conclusión, encontramos que el extracto acuoso liofilizado de $\mathrm{R}$. chalepensis, administrado durante el periodo de organogénesis muestra efectos embriotóxicos en ratones, por esa razón se sugiere no considerar su uso durante el periodo de preñez.

\section{Agradecimientos}

Los autores expresan su agradecimiento a la Bióloga Guadalupe D'Arrigo por su apoyo en la obtención del liofilizado del extracto acuoso de la planta

\section{Literatura citada}

Almeida F., I Lemonica. 2000. The toxic effects of Coleus barbatus B. on the different periods of pregnancy in rats. $J$ Ethnopharmacol. 73:53-60.

Arenas P., G.P. Savitry. 1994 La ruda: Ruta chalepensis (L.) Rutaceae. Dominguezia. 11:7-25.

Benavides V., G. Trujillo, G. D’Arrigo, U. Paredes, J. Pino. 2000. «Evaluación toxicológica preliminar de Ruta graveolens, Origanum vulgare y Persea americana sobre embriones preimplantacionales de ratón». Rev Per Biol. 7(1):86-88.
Berdoncés JL. 1998. Gran Enciclopedia de Las Plantas Medicinales. Barcelona: Tikal

Chávez M., I. Franco, M. González, M. Tlatenco. 2003. Tradición Herbolaria y Remedios Caseros. México City: Ce-Ácatl, A.C. $80-81$ pp.

Conway G.A., J.C. Slocumb. 1979. Plants used as abortifacients and emmenagoges by Spanish New Mexicans. J Ethnopharmacol. 1:241-61.

Di Stasi L.C., C.A. Hiruma, C.M. Guimaraes. 1994. Medicinal plants used in Brazilian Amazon. Fitoterapia. 65:529-540.

Fon Quer P. 1962. Plantas Medicinales. Labor, Buenos Aires, 426 $\mathrm{pp}$.

Gonçalves T., P. Martins, T. Montanari. 2005. Effects of Ruta graveolens L. on pregnant mice. Contraception. 71:74-7.

González M. 1998. Plantas Medicinales del Noreste de México. Monterrey, México: IMSS-Vitro.

Guarrera P.M. 1999. Traditional antihelmintic, antiparasitic and repellent uses of plants in Central Italy. J Ethnopharmacol. 68(1-3):183-192.

Guerra M.O., A.T. Andrade. 1978. Contraceptive effects of native plants in rats. Contraception. 18:191-9.

Hnatyszyn O., P. Arenas, A. Moreno, R. Rondita, J.D. Coussio. 1974. Plantas reguladoras de la fecundidad según la medicina folklórica. Rev Soc Cien. 14:37 pp.

Kimmel C.A., C. Trammel. 1981. A rapid procedure for routine staining of cartilage and bone in fetal and adult animals. Stain Technol. 56:271-3.

Kong Y.C., C.P. Lau, K.H. Wat, et al. 1989. Antifertility principle of Ruta graveolens. Planta Med. 55:176-8.

Lemonica I.P. 1996. In: Oga, S. (Ed.), Fundamentos de Toxicología. Atheneu, Sao Paulo.

Mancebo F., L. Hilje, G.A. Mora, et al. 2001. Biological activity of Ruta chalepensis(Rutaceae) and Sechium pittieri (Cucurbitaceae) extracts on Hypsipyla grandella (Lepidoptera :Pyralidae) larvae. Rev Biol Trop. 49(2):501508.

Melito A.L., MM. Bernardi, J.C. Florio. 2003. Avaliacao da embriofetotoxicidade do extrato bruto de Ruta graveolens L. Admionistrado a camundongos em diferentes períodos de gestacao. Rev Brasil Toxicol. 16:63-70.

Narotsky M., J. Rogers. 2000. Chapter 14. Examination of the axial skeleton of fetal rodents. En: Tuan R. \& Lo C (Eds). Methods in Molecular Biology Vol.135. Developmental Biology Protocols. Vol. I. pp: 139-150. Humana Press. Totowa, NJ.

Ojala T., S. Remes, P. Haansuu, et al. 2000. Antimicrobial activity of some coumarin containing herbal plants growing in Finland. J Ethnopharmacol. 73(1-2):299-305.

Stanley F.J., C. Bower. 1986. «Teratogenic drugs in pregnancy». Med J Australia. 145:596-599

Trovato A., M.T. Monforte, A.M. Forestieri, F. Pizzimenti. 2000. In vitro anti-mycotic activity of some medicinal plants containing flavonoids. Boll Chim Farm. 139(5):225-227.

Zeichen de Sa R., A. Rey, E. Argañaraz, E. Bindstein. 2000. Perinatal toxicology of Ruta chalepensis (Rutaceae) in mice. J Ethnopharmacol. 69:93-98 


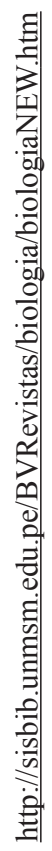

